\title{
Untangling racism: Stress reactions in response to variations of racism against Black Canadians
}

\author{
Kimberly Matheson ${ }^{1,2 凶}$, Andrena Pierre ${ }^{3}$, Mindi D. Foster ${ }^{4}$, Mathew Kent ${ }^{1}$ \& Hymie Anisman ${ }^{1,2}$
}

The ability to effectively contend with racism is likely undermined by factors that promote uncertainty regarding racist motives. A national policy of multiculturalism exists in Canada, which is intended to encourage cultural diversity, but can also serve to mask systemic racism. This may contribute to uncertainty when racism is encountered, with implications for the appraisals, coping, and stress-related outcomes of ethnoracial minorities. Two studies were conducted to assess Black Canadians' experiences of racism, and their reactions to variations in the nature of the experience. A survey study found that Black Canadians' $(n=158)$ selfreported past encounters with explicit racism were associated with anger-out coping, which in turn was related to lower depressive affect. In contrast, ambiguous racism was related to keeping anger in and higher depressive affect; this relation was exacerbated when participants believed Blacks were held in high regard by others, likely adding uncertainty to interpreting behaviours as racist. An experimental study manipulated the nature of racist cues conveyed in a videotaped description of the experiences of a Black male interviewee. When the Black interviewee described racist experiences that were ambiguous (vs. explicit) both White $(n=112)$ and Black $(n=99)$ observers were less likely to appraise events as racist, even when physical violence was involved. However, the moment-to-moment distress elicited while listening the interviewee's description of their racist experiences was uniquely associated with higher cortisol levels among Blacks (but not Whites), especially when physical violence was present. Taken together, the findings contribute to our understanding of the processes by which ambiguous racism might operate to undermine the well-being of targeted groups. Moreover, it is suggested that policies conveying that ethnoracial groups are highly valued (e.g., multiculturalism) might actually exacerbate negative effects of racist experiences, particularly in the absence of an open discourse acknowledging the presence of systemic racism.

\footnotetext{
${ }^{1}$ Department of Neuroscience, Carleton University, Ottawa, Canada. ${ }^{2}$ University of Ottawa Institute of Mental Health Research, Ottawa, Canada.

${ }^{3}$ Department of Psychology, Carleton University, Ottawa, Canada. ${ }^{4}$ Department of Psychology, Wilfrid Laurier University, Waterloo, Canada.

凶email: kim.matheson@carleton.ca
} 


\section{Introduction}

ocial norms among most Western liberal societies discourage blatant racist attitudes. Yet, the emergence of the Black Lives Matter movement in the United States has pointed to racism being alive and active. Indeed, under the presidency of Donald Trump, a visible shift in social norms occurred that condoned expressions of blatant racism and claims of White victimization, which fostered the establishment of social policies that were clearly racialized (Bloch et al., 2020). At the same time, to the north, in Canada, there were notable assertions that 'racism does not exist in Canada' (Lum, 2020), bolstered by the pervasive belief that Canadians embrace multiculturalism (Dunn and Nelson, 2011). Nonetheless, according to a recent national survey (Neuman, 2019), the majority of Canadians acknowledge that racism occurs at least occasionally, and that Blacks ${ }^{1}$ and Indigenous peoples (First Nations, Inuit, and Métis) are especially likely to experience racism. There remains, however, little acknowledgement of structural or systemic racism (i.e., 'racism without racists'), and even less recognition of the impact of minor day-to-day instances of subtle racism (e.g., microaggressions), or behaviours that have been described as 'racism with a smile' (Jones, 2020; Kunstman et al., 2016). At the same time, these subtle or ambiguous racist acts are especially likely to undermine the well-being of members of ethnoracial groups (Jones et al., 2016).

Based on Canadian census data, there are 1.2M Black Canadians, comprising $3.9 \%$ of the population (Statistics Canada, 2019) (compared to $13.4 \%$ of Americans). Approximately $52 \%$ of Blacks reside in the province of Ontario. The majority (over 60\%) are immigrants, contributing to more than a doubling of the Black population in Canada since the mid-1990s. While the majority of immigrants came from Caribbean countries (Jamaica, Haiti), this has been shifting with increased immigration and asylum seeking from African countries (Statistics Canada, 2019). Thus, the explicit subjugation of Blacks is less integrated in Canadian historical and legislative policies than is the case of Indigenous peoples or in comparison to the experiences of African Americans. Although there exist racially segregated urban areas (Ray and Preston, 2015), this segregation can be linked to numerous factors, including differences of socio-economic status, and social clustering based on national origins.

Canadian identity is commonly tied to multiculturalism, embraced as a celebration of diversity and tolerance. At the same time, it has been suggested that multiculturalism is a screen behind which many Canadians wilfully withdraw from a responsibility to challenge contemporary mechanisms supporting racism (Dunn and Nelson, 2011), and indeed, many Canadians seem perplexed by assertions of systemic racism. It was the goal of the present investigation to assess the implications of experiences of racism among Black Canadians within the unique sociopolitical context of Canada.

Given the historical roots of the Black population in Canada, together with the principle of multiculturalism that many Canadians believe is inherent to national policies and to their own actions, the experience and interpretation of racist encounters may be especially ambiguous. Such ambiguity may have consequences for Black Canadians' ability to contend with such encounters, as well as for their health and well-being. The present investigation assessed whether Black Canadians' past experiences of racism were associated with internalizing emotional reactions; such reactions might be especially pronounced when Black Canadians' believe that their societal contribution is valued by others. A second study was conducted to explore Blacks' and Whites' appraisals of ambiguous versus explicit racist events targeting a Black victim, and the extent to which exposure to such events elicited differences in emotional (distress, anger) and physiological (cortisol) reactions. This experimental study systematically distinguished the severity versus ambiguity of racist experiences to determine how these features causally influenced the interpretations and emotional responses of Black and White Canadians.

Racism as a stressor. The impacts of racism have increasingly been addressed within a stress and coping framework that allows for the elucidation of the links between racist encounters, and the cognitive, emotional, and physiological responses that promote stress-related illnesses (DeLapp and Williams, 2019). To the extent that racism is perceived as pervasive, it represents a threat to well-being, eliciting negative emotions, including anger and distress, among targeted individuals (Pieterse et al., 2012; Schmitt et al., 2014). Concurrently, multiple neurobiological coping processes are triggered that may become overly taxed (allostatic overload; McEwen and Akil, 2020), rendering individuals vulnerable to the development of stress-related psychological illnesses (e.g., depression, anxiety and posttraumatic stress disorder), as well as numerous physical disorders (e.g., Type II diabetes, heart disease, and inflammatory related disorders) (Anisman et al., 2018).

Under most conditions, and for most people, coping strategies are relatively effective in diminishing the threat and maintaining well-being. However, an effective coping response to racism may be undermined when ambiguity exists regarding whether the experience constituted racism, as the targeted individual may be concerned about whether the behaviour was intentionally offensive, whether they merited such treatment, and whether their own behaviour elicited such actions (Major et al., 2002; Quinn et al., 2014). Under these conditions, the well-being of ethnoracial group members may be harmed to an equal, if not greater, degree than when faced with more explicit racist acts (Jones et al. 2016; Lui and Quezada, 2019; Matheson et al., 2019). When racism is blatant, it can be labelled as such, thereby reducing uncertainty about how to cope, justifying feelings of outrage, and mobilizing supports to engage in collective advocacy (Ellemers and Baretto, 2009). In contrast, a meta-analysis revealed consistent relations between experiencing microaggressions (subtle or ambiguous discrimination) and internalizing affective outcomes (depression, anxiety) (Lui and Quezada, 2019).

Not all members of ethnoracial groups experience such consequences, and some individuals appear to be protected against the negative effects of racism. In this respect, positive regard for one's ethnic identity conveys a collective strength that may allow group members to be sensitive to relevant cues (Operario and Fiske, 2001), but at the same time, enables them to 'call out' racism when it occurs. Sensitivity to such cues varies as a function of ethnic group (Forrest-Bank and Jenson, 2015), past experiences with discrimination (Lui, 2020), beliefs about interracial interactions (e.g., rejection sensitivity, system justification) (Mercer et al., 2011), and personality differences (e.g., neuroticism) (Lilienfeld, 2017). It appears that numerous contextual and individual difference factors influence appraisals of a racist encounter, which might, in turn, have implications for well-being.

Survey study. A survey study was conducted to assess the extent to which explicit versus ambiguous experiences of racism were associated with particular emotional coping responses that, in turn, were linked to depressive affect among Black Canadians. Of the varied emotions elicited by racism, anger that stems from perceptions of injustice is common (Broudy et al., 2007; Ellemers and Barreto, 2009; Van Zomeren et al., 2004). When anger is elicited, it can motivate group members to cope by expressing or 
acting on their outrage (i.e., anger-out), holding the perpetrator group accountable, and mobilizing collective efforts for change (Brondolo et al., 2005; Ellemers and Barreto, 2009; Gill and Matheson, 2006; Van Zomeren et al., 2004). In contrast, given that ambiguous discrimination tends to be related to internalizing emotional outcomes (Lui and Quezada, 2019), we anticipated that anger associated with such events might likewise be suppressed (i.e., keeping anger in). Emotional suppression tends to engender inaction and self-attributions for the negative experience (Gill and Matheson, 2006; Sosoo et al., 2019). Thus, a second goal of the survey study was to assess the unique relations between explicit and ambiguous experiences of racism with externalizing (angerout) versus internalizing (anger-in) emotional coping responses, respectively, and the extent to which these emotions were tied to depressive affect.

A third goal of the survey study was to determine whether the appraisal-coping process was influenced by ethnoracial identity. Group identities are multidimensional with varying implications for how the individual contends with racism (Bombay et al., 2010; Brittian et al., 2015; Sellers et al., 2006). The affective connection between the individual and their group is reflected in feelings of pride (i.e., private regard for one's group), as well as in relation to perceptions of the attitudes held by others toward one's group (i.e., public regard) (Sellers et al., 1998). Positive affect stemming from high private regard may buffer against negative consequences (Bombay et al., 2010; Forrest-Bank and Cuellar, 2018), perhaps because the shared experience of racism consolidates group identity and solidarity (Branscombe et al., 1999; Giamo et al., 2012). However, much like the principles of multiculturalism, high public regard may create uncertainty regarding the interpretation of racist experiences. As a result, negative emotional outcomes were expected to be more evident among Blacks who perceived high public regard.

Experimental study. As a self-report survey does not allow for causal conclusions, a second study assessed appraisals, emotional, and physiological stress reactions to ambiguous and explicit racism by exposing Canadian Blacks and Whites to a manipulation of racist cues in an experimental setting. Although participants were not directly discriminated against, but rather watched a videotaped interview with the target of racism, observing such interactions can trigger a powerful identity threat response (Matheson and Anisman, 2012).

Reactions to ambiguity are typically examined in the context of microaggressions, which themselves tend to be subtle or mild forms of racism (Hoggard et al., 2017; Sue, 2010; Tao et al., 2017). Yet, racism is among the top motivators of violent behaviour, accounting for more than half of all recent hate crimes in the United States (Gong et al., 2017). Similarly, contrary to widely held beliefs within Canada, a Black person is 20 times more likely to be shot and killed by police relative to a White person (Stelkia, 2020). At the same time, many Whites do not appear to connect how systemic racism can result in violence and even death, and when violent interracial encounters occur, many view them as the actions of a maverick individual, rather than constituting racism. One objective of the experimental study was to untangle the confound between the ambiguity and severity of racist events by employing a design wherein ambiguous versus explicit cues were crossed with whether the events were mild (i.e., might be encountered on a day-to-day basis) or included physical violence.

In addition to considering emotional responses to diverse expressions of racism, we assessed the cortisol reponse to these experiences. Typically, stressors promote a cascade of biological changes that prepare the person to deal with the threat, and to blunt adverse physiological and psychological impacts. In this regard, activation of hypothalamic-pituitary-adrenal (HPA) processes, culminating in release of adrenal cortisol, is a functionally adaptive response to stressful stimuli (Sapolsky et al., 2000). The relation between stressful encounters and cortisol reactivity to laboratory and to natural challenges is particularly pronounced when they elicit shame or were characterized by a lack of control (Dickerson and Kemeny, 2004; Michaud et al., 2008). Thus, to the extent that discrimination is associated with internalizing emotions (such as shame or distress), elevated cortisol might be expected to occur.

Cortisol reactivity may be further influenced by prior stressor experiences. Chronic stressors such as racism may result in downregulated cortisol reactivity, perhaps as an adaptive response to prevent downstream negative outcomes (Matheson and Anisman, 2012). This said, upon exposure to salient reminders of these stressors, a stronger cortisol response may be elicited, perhaps owing to the sensitization of processes associated with HPA functioning (Anisman et al., 2018). At the same time, past racism experiences can mobilize 'accumulated resources' that enable ethnoracial group members to appraise discrimination experiences as such, contribute to effective coping, and buffer against stress-related outcomes (DeLapp and Williams, 2019). Thus, the experimental study assessed emotional (anger, distress) and cortisol responses elicited by ambiguous or explicit racist cues as a function of Black Canadians' past experiences of racism.

Racism is an intergroup experience, not constrained to the impacts on targeted ethnoracial minorities. In this regard, witnesses to discrimination may report negative emotional reactions (Schmader et al., 2012), particularly in response to explicit racism (Tao et al., 2017; Torres et al., 2020), although other studies reported more apathetic reactions (Karmali et al., 2017). As social norms encourage multiculturalism and antiracism, sincerity may or may not be at the foundation of liberal Whites' responses (Radke et al., 2020; Torres et al., 2020). Indeed, 'modern racism' (McConahay, 1986) is expressed by attributing differential values and attitudes that serve to justify group inequities, or advocating that enough change has occurred to alleviate them. As a result, when racial injustices are made salient, modern racist biases might elicit indifference to the target group's suffering (Passini, 2019). Thus, the concurrence between Canadian Whites' self-report appraisals and indicators of their reactions that are less amenable to response biases (namely their moment-to-moment emotions and cortisol reactivity to racist cues), and whether these processes were moderated by modern racist beliefs might provide insight into Whites' reactions to racism.

\section{Methods}

\section{Survey study}

Participants and procedures. Black participants $(n=158)$ were recruited through advertisements posted on various public websites, newspapers and community flyers, and signs posted on public bulletin boards of community centres, service organizations, and workplaces. They were invited to participate in a survey regarding Canadian Life Experiences, either online or in paper format exchanged by mail. Upon submission of their survey responses, participants were provided a written debriefing and were entered into an instant draw lottery for a $\$ 10$ gift certificate, as well as a $\$ 500$ lottery held at the end of data collection. Both the survey and experimental studies were approved by the research ethics boards at Carleton University and Wilfrid Laurier University.

The majority of respondents were female $(n=106,67.5 \%$; males $n=51,32.3 \% ; 1$ person did not disclose), and ages ranged from 16 to 65 years $(M=26.03, S D=9.39)$. Most were Canadian 
citizens $(80.4 \%)$ or landed immigrants $(7.6 \%)$, although some were in Canada on temporary (student) visas (12.0\%). The majority $(80.3 \%)$ had some undergraduate or college education.

Measures. The Perceived Ethnic Discrimination Questionnaire (Contrada et al., 2001) comprised 22 items assessing experiences of explicit day-to-day racism (e.g., ethnic slurs, insults, denial of equal treatment, actual or threatened harm), and a further 22 items were included to assess ambiguous racism encounters (e.g., "Sometimes I'm not sure if what I'm seeing or hearing is racist"). Respondents rated how often they had encountered each experience over the past 3 months from 1 (never happened) to 7 (happened very often), and ratings were averaged to reflect perceptions of explicit (Cronbach's $\alpha=0.93$ ) and ambiguous racism (Cronbach's $\alpha=0.94$ ).

The Multidimensional Inventory of Black Identity (Sellers et al., 1998) assessed private regard (six items, e.g., "I feel good about Black people") and public regard (six items, e.g., "In general, others respect Black people"). Agreement with each statement was indicated using a -3 (strongly disagree) to 3 (strongly agree) rating scale, and average ratings for each subscale formed the basis of indices of private (Cronbach's $\alpha=0.77$ ) and public regard (Cronbach's $\alpha=0.83$ ).

Two subscales from the Multidimensional Anger Inventory (Siegel, 1986) were administered, namely anger-out (e.g., "When I'm angry with someone, I let that person know") (2 items, $r=0.56$ ) and anger-in (e.g., "I harbour grudges that I don't tell anyone about") ( 4 items, Cronbach's $\alpha=0.72$ ). Participants rated how much each statement applied to them on a scale ranging from 1 (not at all) to 5 (completely).

Depressive affect was assessed using the 21 -item version of the Beck Depression Inventory (Beck et al., 1961). For each question, participants chose from one of four responses (coded 0-3), with each response reflecting increasing symptom severity. Summed scores could range from 0 to 63 (Cronbach's $\alpha=0.88$ ).

\section{Experimental study}

Participants. Black $(n=99)$ and White $(n=112)$ participants were recruited from a booth set up at the Ontario Science Centre $(n=47)$ in Toronto, Canada, as well as through postings at a Canadian university $(n=164)$. The study was described as concerning reactions to various experiences in the Canadian workplace. University participants were paid $\$ 10$ or given experimental credit for their participation.

The age ranges of Black $\left(M_{\text {age }}=20.7, S D=4.80\right.$; range 16-42 years) and White $\left(M_{\text {age }}=22.0, S D=7.04\right.$; range $16-47$ years) participants were equivalent. The majority of both Black (55 females, 41 males; 3 unspecified) and White participants (78 females, 34 males) were female. Most had completed high school diplomas (Black $n=47$; White $n=45$ ) or $1-3$ years of university (Black $n=38$; White $n=49$ ), although a few had completed either an undergraduate or graduate degree (Black $n=9$; White $n=10)$.

Procedures. Because cortisol varies in a diurnal fashion, participants were tested between 11:30 and 17:00 hours. They were asked to not eat, drink, or smoke for $30 \mathrm{~min}$ prior to the study. At the outset of the session, participants were provided with an overview of the procedures, written informed consent was obtained, and after completing background information measures, they were randomly assigned to watch one of five videotaped interviews that varied in the severity and explicitness of racism. The videos were linked (via the computer) to a wireless interactive hand-held dial through which participants conveyed their moment-to-moment emotional distress to statements made by the interviewee. At three timepoints during the videos, participants appraised the events depicted (presence of discrimination, seriousness of impact). Following the videos, they completed a measure of feelings of anger, and past discrimination experiences (Blacks) or modern racist attitudes (Whites). Finally, participants were debriefed, and provided with contact numbers should they experience any distress or have any human rights concerns, and provided with experimental credit or payment.

Video materials. Each of the videos depicted an interview in the context of a local daily news programme that was conducting a series on "Working in Ontario: Meeting employee needs". The videos were professionally created using well-rehearsed nonprofessional actors. In all five conditions, a white male host interviewed a Black male in his mid-20s. The same actors were used in all conditions.

All of the videos began with the host asking questions about the guest interviewee's workplace. The first segment ( $2.5 \mathrm{~min})$ was the same across all conditions, wherein the guest described his career history working up to his current position as a Graphics Designer for a large firm. Responses were fact-based, along with comments that depicted the workplace environment as mildly stressful (e.g., small office, crowded conditions). The second segment of the video interview $(6 \mathrm{~min})$ built on these features to describe mildly stressful social interactions, as well as workplace limitations, such as challenges in career advancement. Descriptions of these events varied to reflect no racism, explicit mild racism, or ambiguous mild racism. For example, in all videos, the interviewee described how he felt when he was successfully promoted. In the no racism video, the interviewee reported "I still wonder whether people think that I really deserved the job-you know, some of us just don't have the self-confidence to promote ourselves well", whereas in the explicit mild racism video, he indicated "I still hear people say that the only reason I got the job was because they needed to promote a Black to avoid having to implement an affirmative action quota plan." In the ambiguous racism video, the interviewee expresses uncertainty about others' attributions for his success, "I still wonder whether people think that I got the job because they know I was the best person, or whether they think it was because our firm had to promote a Black to avoid having to implement an affirmative action quota plan."

Finally, the third segment of the video ( $3.5 \mathrm{~min}$ ) asked the interviewee questions about his encounters with his colleagues outside the workplace. There were five variations of this segment of the video. In all of five conditions, he describes an experience of going to a local bar after work. The description includes tensions in organizing the group to get to the bar, the rudeness of his colleagues to the bartender, and their negative reaction to him when he suggested they alter their behaviour, and his decision to leave the bar. In the no racism, explicit and ambiguous mild racism conditions the interviewee's description ended here. To introduce physical violence that was ambiguous, in a fourth condition (that built from the no racism scenario in segments 1 and 2), the interviewee describes his decision to leave the situation, "I went out to wait for the cab, and that's where he was, waiting for me. I tried to turn to go back into the bar, but he blocked my way. I turned to walk away, and he grabbed me from behind, and said 'no-one talks to me like that in front of my buddies. You gotta know your place, and I'm going make sure you never forget.' He jerked me by the throat and threw me to the ground. But then I was lucky-I heard a siren start right behind us, and he ran. I had blood running down my face from a cut I got from broken glass on the ground. The cops asked me whether I knew the guy, but I was afraid to turn him in. I had to work with him, and it might have ended my career to start trouble." In the 
fifth condition (which built on the mild explicit racism reported in segment 2), the violence was described as explicitly racist through the inclusion of explicit language, and highlighting that these were not the isolated actions of a single individual"....the guy that I'd confronted put his arms around my neck from behind, and said 'no Black boy gets away with talking to me like that in front of my buddies. You gotta know your place, and I'm going make sure you never forget.' He jerked me by the throat and threw me to the ground. The other guys started to laugh. But then I was lucky-I heard a siren start right behind us, and they all ran. I had blood running down my face from a cut I got from broken glass on the ground. The cops asked me what I did to start the fight. I started to protest, but I was afraid to turn in the other guys. It might have ended my career to say anything."

Salivary cortisol. Saliva collection comprised participants placing a piece of dental cotton in their cheek for a 2-min period. Once the cotton was thoroughly wet, it was placed in a test-tube for subsequent analysis. This procedure was conducted three times: baseline levels were assessed $15 \mathrm{~min}$ after arrival at the test session, but before watching a video; and then again 10 and $20 \mathrm{~min}$ after watching the video. Based on our earlier studies, these times represent peak saliva cortisol levels following a stressor (Matheson and Anisman, 2009). Cortisol levels were determined, in duplicate, by means of a solid phase radio-immuno assay using ${ }^{125}$ I kits (ICN Biomedicals Inc., CA). The intra- and extra-assay variability was $<10 \%$.

Time of day at which samples were collected was not significantly related to cortisol levels at any time point, nor were there significant differences in time of day across racist cues conditions or ethnic group. In addition, among the female participants, current use of oral contraceptives was not related to levels of cortisol at any of the three time points. For the purposes of analyses, area under the curve with respect to zero was calculated for each participant (formula 3, Pruessner et al., 2003).

Measures. Appraisals of the experiences the interviewee described in the videos were assessed after each of the three segments. This comprised two items assessing whether his experiences constituted discrimination and participants' confidence in their determination of whether the events were due to discrimination, ranging from -3 (not at all) to +3 (definitely) $(r s=0.40,0.81$, 0.79, ps $<0.001$, between the two items at each measurement time, respectively). The perceived seriousness of the situation was assessed by two items, including ratings (from -3 to +3 ) of 'how serious do you think the events that have been described so far are in terms of their impact on the employee's career' and on his 'psychological well-being' $(r s=0.37,0.38,0.40, p s<0.001$ for each time point, respectively).

The videos were synchronized with a wireless interactive dial through which participants conveyed ongoing emotional reactions (how distressed or anxious they felt on a scale of $0-10$ ) to statements made by the interviewee. Moment-to-moment ratings were captured at 1 second intervals. As a result, there were about 150 ratings for the first section of the video, 370 for the second, and 200 for the third. For each of the three video segments, distress ratings were averaged to provide an index of distress for each segment.

After watching the videos, participants' feelings of anger were assessed using five mood adjectives (angry, annoyed, enraged, infuriated, irritated) with ratings from 0 (not at all) to 6 (extremely) (Cronbach's $\alpha=0.90$ ).

To assess Black participants' experiences of discrimination over the past 6 months, they responded to eight questions, each of which tapped into the dimensions reflected in the Personal Experiences of Discrimination Questionnaire (e.g., 'How often have you been called names or heard offensive comments because of your ethnic group membership, spoken either in your presence or behind your back?'). Responses ranged from 1 (never) to 7 (very often) and were averaged to reflect past discrimination experiences $(M=3.06, S D=1.26$; Cronbach's $\alpha=0.84)$.

White participants responded to four questions selected from a measure of modern sexist biases in Canada (Tougas et al., 1995), modified to refer to Blacks (e.g., 'Blacks shouldn't push themselves where they are not wanted'). Ratings of agreement, from 0 (strongly disagree) to 5 (strongly agree), were averaged to provide an index of modern racist attitudes $(M=0.43, S D=1.26$; Cronbach's $\alpha=0.60$ ).

\section{Results}

\section{Survey study}

Descriptives. Black participants reported experiencing both explicit $(M=2.58, \quad S D=1.01)$ and especially ambiguous $(M=3.03, S D=1.23)$ forms of racism, $t(140)=-4.97, p<0.001$, $r=0.54, p<0.001$. Both explicit, $r=-0.26, p=0.002$, and ambiguous, $r=-0.25, p=0.003$, experiences of racism were associated with lower public regard, but neither type of racism was related to private regard, $r \mathrm{~s}=-0.08$, ns. In addition, males indicated more frequent encounters with explicit discrimination $(M=2.81, S D=1.19)$ than did females $(M=2.44, S D=0.88), F$ $(1,140)=4.26, p=0.041$. There were no gender differences in experiences of ambiguous racism, private or public regard, angerout, anger-in, or depressive affect.

Unique effects of explicit and ambiguous racism. Multiple regression analyses were conducted to assess the relations between explicit and ambiguous racism experiences (entered simultaneously) and each of anger-out and anger-in coping strategies, and depressive affect (outcomes). As expected, explicit racism experiences were associated with greater anger-out, $r=0.16, b=0.31$, se $=0.11, p=0.006$, with ambiguous racism appearing to serve as a suppressor variable, $r=-0.08, b=-0.25$, $s e=0.11, p=0.024 ;$ full model $F(2,134)=5.81, p=0.004$, $R^{2}=0.080$. Thus, when controlling variance associated with ambiguity, the relation between explicit experiences and angerout was strengthened. In contrast, ambiguous racism was related to greater anger-in, $r=0.28, b=0.22, s e=0.07, p=0.002$, whereas explicit racism was not, $r=0.10, b=-0.06$, $s e=0.09$, $p=0.496$; full model $F(2,133)=4.37, p=0.015, R^{2}=0.062$.

When predicting depressive affect, explicit racism served as the suppressor variable, $r=0.14, b=-0.21$, se $=0.86, p=0.810$, enhancing the relation between ambiguous encounters and greater depressive affect, $r=0.29, b=1.90$, se $=0.68, p=0.006$; full model $F(2,109)=5.08, p=0.008, R^{2}=0.085$. In effect, when the contribution of ambiguity was isolated (by controlling explicit racism), ambiguity was more strongly related to depressive affect.

Moderating role of private and public regard for Blacks. To assess whether the relations between racism and anger coping were moderated by private or public regard, regressions were conducted using PROCESS macro (Version 3.3) model 1, centering continuous predictor variables prior to calculating the interaction (Hayes, 2017). These analyses indicated that over and above the relation with explicit racism, $b=0.21, s e=0.09, p=0.026$, higher private regard predicted greater anger expressed outwardly, $b=0.36, s e=0.12, p=0.003$. The interaction between explicit racism and private regard was not significant, $b=-0.03$, $s e=0.10, p=0.791 ;$ full model $F(3,134)=4.42, \quad p=0.005$, $R^{2}=0.090$. Perceived public regard was not associated with anger-out. 


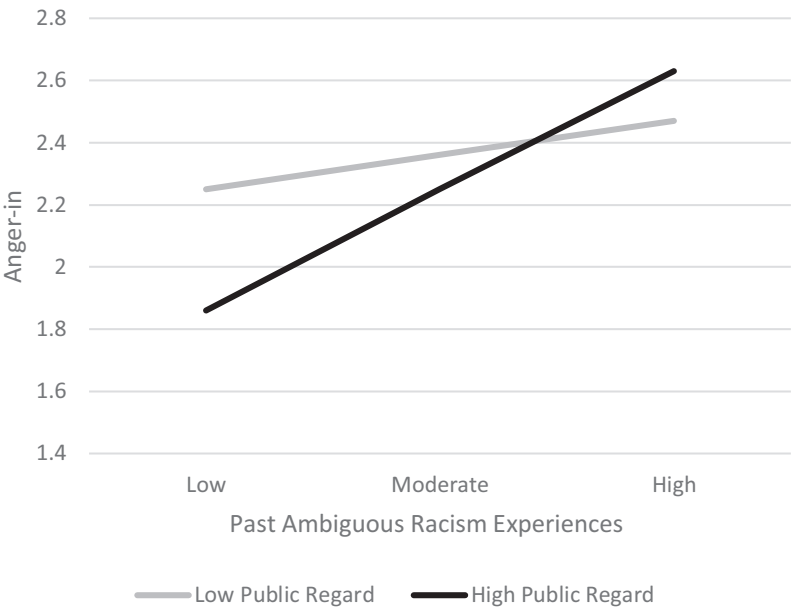

Fig. 1 Mean ratings of anger-in as a function of past experiences of ambiguous racism and the moderating role of perceived public regard for Blacks in the survey study. When participants believed that Blacks were held in low public regard (1 SD below the mean), ambiguous racist experiences were not related to anger-in. As perceived public regard became higher ( $1 S D$ above the mean), there was a increasingly positive relation between experiencing ambiguous racism and holding anger-in.

Whereas perceptions of public regard for Blacks were not directly related to anger-in, $b=-0.08, s e=0.06, p=0.161$, public regard moderated the relation between ambiguous racism and anger-in, $b=0.11$, se $=0.04, p=0.010$; full model $F$ $(3,132)=6.38, p<0.001, R_{\text {cha }}^{2}=0.127$. As seen in Fig. 1 , simple slopes analyses indicated that when others were perceived to view Blacks negatively (low public regard), ambiguous racist experiences were not associated with anger-in, $b=0.06$, se $=0.07$, $p=0.402$. In contrast, as public regard for Blacks increased, so too did the association between ambiguous racism and holding anger in, $b=0.34$, se $=0.09, p<0.001$. Private regard was not associated with anger-in.

Mediating role of anger coping in the relations between racism and depressive affect. To determine whether anger mediated the relations between experiences of racism and depressive affect, the PROCESS macro applying model 4 (Hayes, 2017) was used. These analyses were followed up to determine whether private or public regard moderated the mediated models using PROCESS model 7. The macros used bootstrapping procedures with 5000 resamples to establish the $95 \%$ confidence intervals (CI) to assess significance of the path coefficients.

The total effect of explicit racism in relation to depressive affect was not significant, $c=1.27$, se $=0.79, \mathrm{CI}_{.95}[-0.29,2.84]$, but with the inclusion of anger-out as a mediator, a direct effect of explicit racism was apparent, $c^{\prime}=1.75, s e=0.78, \mathrm{CI}_{.95}[0.20$, 3.31]. The mediated path between explicit racism and depressive affect through anger-out was also significant, $a b=-0.48$, $s e=0.27, \mathrm{CI}_{.95}[-1.10,-0.06]$. In essence, with anger-out controlled, explicit racism was related to greater depressive affect. Conversely, when explicit racism was associated with greater expression of anger, lower depressive affect was reported (mediation). Private regard did not moderate this mediated model.

The total effect of experiencing ambiguous racism in relation to greater depressive affect was significant, $c=1.82$, $s e=0.57, \mathrm{CI}_{.95}$ $[0.69,2.95]$. With the inclusion of anger-in as a mediator, the direct effect remained significant, $c^{\prime}=1.61, s e=0.57, \mathrm{CI}_{.95}[0.47$, $2.75]$, and the mediated effect through anger-in was marginally significant, $a b=0.21$, se $=0.14, \mathrm{CI}_{.90}[0.02,0.48]$. Public regard significantly moderated this mediated model, Index $=0.15$, $s e=0.09, \mathrm{CI}_{.95}[0.002,0.36]$, in that, the mediated pathway between ambiguous racism and depressive affect through angerin was evident at higher, $a b=0.27$, $s e=0.14, p=0.012$, but not lower, $a b=0.02$, se $=0.08, p=0.826$, levels of public regard.

Summary of survey results. Consistent with past research (Lui and Quezada, 2019), experiences of explicit racism were associated with expressing anger, whereas ambiguous experiences were related to suppressing anger. Moreover, when the ambiguity was controlled, the relation between explicit racism and anger-out was strengthened (i.e., the suppressor effect), and higher private regard (Black pride) was additively related to anger-out. To the extent that explicit racism was related to anger being expressed, lower depressive affect was evident. This said, when anger-out was controlled, explicit racism was associated with higher depressive affect.

In contrast, the relation between ambiguous racism and angerin remained after controlling the experience of discrimination itself (explicit racism) and was exacerbated when combined with the additional uncertainty associated with thinking that others held Blacks in high regard. This suggests that ambiguity in itself represents a threat to individuals' well-being, potentially undermining effective strategies to confront the situation, and hence higher depressive affect.

Experimental study. As seen in Table 1, the experimental design involved five conditions in which racist cues were manipulated in the context of a videotaped interview with a Black male interviewee. To assess participants' responses to racist cues, 2 (ethnoracial group: Black vs. White) $\times 5$ (racist cues: no racism, ambiguous racism (violent vs. mild), and explicit racism (violent vs. mild) $) \times 3$ (video segment) mixed measures analyses of variance (ANOVAs) were conducted. Simple effects analyses involved orthogonal contrasts comparing (i) the no racism condition to the four racism conditions, (ii) ambiguous vs. explicit racism, and (iii) violent vs. mild events within each of the ambiguous and explicit racism conditions.

Female participants appraised the videos overall as being more discriminatory $(M=1.69, S D=1.76)$ than did males $(M=1.17$, $S D=2.14), F(1,201)=4.57, p=0.034$, and also expressed greater distress $(M=2.70, S D=2.43)$ than did males $(M=1.98$, $S D=2.10), F(1,201)=5.97, p=0.015$. Gender differences were not moderated by ethnoracial group nor racial cues.

Effects of racial cues on appraisals. As expected, appraisals of whether the events described in the video comprised discrimination varied across video conditions, $F(8,400)=27.91, p<$ $0.001, \eta^{2}=0.358$. Ethnoracial group further moderated the effects of racist cues on discrimination appraisals, $F(4,200)=3.40$, $p=0.01, \eta^{2}=0.064$. As seen in Fig. 2, there were no differences in appraisals at the outset of the video (recall that this segment was identical across conditions). The second segment introduced ambiguous mild racism in the relevant condition, and explicit mild racism in two of the conditions. Indeed, greater discrimination was perceived in these three conditions, in contrast to those in which racism was not yet introduced, $t(204)=10.95$, $p<0.001$. In addition, Whites perceived these events to be less discriminatory than did Blacks, $F(1,200)=14.34, p<0.001$, $\eta^{2}=0.067$. Further seen in Fig. 2 , by the third segment, in which conditions involving physical violence were introduced, both Blacks and Whites were more likely to perceive the conditions involving explicit racist cues as more discriminatory than when cues were ambiguous, $t(200)=7.13, p<0.001$. Explicit racist events were perceived as being equally discriminatory, 
Table 1 The experimental study entailed Black $(n=99)$ and White $(n=112)$ participants assigned to watch one of five videos created for this study to manipulate racist cues.

\begin{tabular}{|c|c|c|c|c|c|c|c|}
\hline \multicolumn{2}{|l|}{$\begin{array}{l}\text { Racist cues } \\
\text { condition }\end{array}$} & \multicolumn{2}{|l|}{$\begin{array}{l}\text { Segment } 1 \\
\text { of video }\end{array}$} & \multicolumn{2}{|l|}{$\begin{array}{l}\text { Segment } 2 \\
\text { of video }\end{array}$} & \multicolumn{2}{|l|}{$\begin{array}{l}\text { Segment } 3 \\
\text { of video }\end{array}$} \\
\hline No racism & $\begin{array}{l}\text { Baseline saliva } \\
\text { sample } \\
\text { (cortisol) }\end{array}$ & $\begin{array}{l}\text { Mild day-to-day } \\
\text { workplace } \\
\text { stressors }\end{array}$ & $\begin{array}{l}\text { Appraisals } \\
\text { (discrimination, } \\
\text { severity) }\end{array}$ & $\begin{array}{l}\text { Mild day-to-day } \\
\text { workplace } \\
\text { stressors }\end{array}$ & Appraisals & $\begin{array}{l}\text { Mild day-to-day } \\
\text { workplace } \\
\text { stressors }\end{array}$ & $\begin{array}{l}\text { Appraisals }(-3 \\
\text { to }+3)\end{array}$ \\
\hline $\begin{array}{l}\text { Ambiguous/ } \\
\text { violent }\end{array}$ & & & & & & $\begin{array}{l}\text { Ambiguous racist } \\
\text { violence }\end{array}$ & $\begin{array}{l}\text { Anger ratings } \\
(0-6)\end{array}$ \\
\hline Ambiguous/ & & & & Ambiguous/ & & Ambiguous & Saliva samples \\
\hline mild & & & & mild racism & & mild racism & $10 \& 20 \mathrm{~min}$ \\
\hline Explicit/violent & & & & $\begin{array}{l}\text { Explicit/ } \\
\text { mild racism }\end{array}$ & & $\begin{array}{l}\text { Explicit racist } \\
\text { violence }\end{array}$ & post video \\
\hline \multirow[t]{3}{*}{ Explicit/mild } & & & & & & Explicit & \\
\hline & & & & & & mild racism & \\
\hline & & \multicolumn{6}{|c|}{ Moment-to-moment distress ratings $(0-10)$} \\
\hline $\begin{array}{l}\text { Baseline cortisol mea } \\
\text { interviewee described } \\
\text { segment introduced } n \\
\text { conditions (involving } \\
\text { participants provided } \\
\text { indices of distress. Ap }\end{array}$ & $\begin{array}{l}\text { es were taken, and } t \\
\text { ild everyday workpla } \\
\text { racism that was am } \\
\text { same actions as the } \\
\text { ment-to-moment rat } \\
\text { aisals of whether the }\end{array}$ & $\begin{array}{l}\text { stressors that anyone } \\
\text { iguous or explicit. The } \\
\text { mbiguous conditions, } \\
\text { gs (from } 0 \text { to } 10 \text { ) of } t \\
\text { vents were discrimina }\end{array}$ & $\begin{array}{l}\text { ght encounter; such i } \\
\text { rd video segment pre } \\
\text { he interviewee was e } \\
\text { distress associated } \\
\text { and the seriousness }\end{array}$ & $\begin{array}{l}\text { events continued to be } \\
\text { o ambiguous condition } \\
\text { rgeted due to race). Th } \\
\text { ents described; these } r \\
\text { pact on the interviewe }\end{array}$ & $\begin{array}{l}\text { ribed in all thre } \\
\text { ild vs. an event } \\
\text { hout the videos, } \\
\text { were averaged } \\
\text { e taken followin }\end{array}$ & $\begin{array}{l}\text { wee. In the first segment } \\
\text { segments in the No Racis } \\
\text { volving physical violence } \\
\text { sing a hand-held device s) } \\
\text { within each of the three se } \\
\text { each of the three video s }\end{array}$ & $\begin{array}{l}\text { in all conditions the } \\
\text { n condition. The second } \\
\text { and two explicit racism } \\
\text { nchronized to the video } \\
\text { gments to provide three } \\
\text { gments, and at the end }\end{array}$ \\
\hline
\end{tabular}

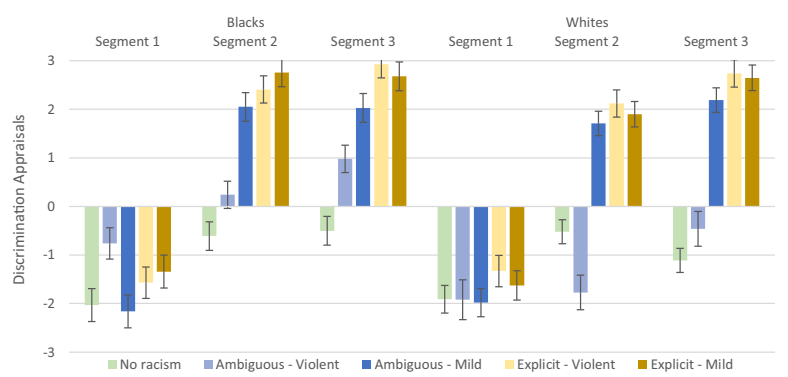

Fig. 2 Mean ratings $( \pm s e)$ of discrimination appraisals as a function of racist cues (five conditions) in the three video segments among Black (left) and White (right) participants. There were no differences in appraisals of discrimination in Segment 1. The second segment introduced ambiguous mild racism in the relevant condition, and explicit mild racism in two of the conditions (labelled explicit mild and explicit violent), at which point greater discrimination was perceived in these three conditions, particularly among Blacks. By the Segment 3, in which conditions involving physical violence were introduced, both Blacks and Whites were more likely to perceive the conditions involving explicit racist cues as discriminatory, irrespective of the presence of violence. When cues were ambiguous, participants were less likely to appraise the violent situation as discriminatory, particularly among Whites.

irrespective of the presence of violence, $t(200)=0.53, p=0.60$. When cues were ambiguous, participants were less likely to appraise the violent situation as discriminatory, $t(200)=-5.92$, $p<0.001$; this interacted with ethnoracial group, $t(200)=2.28$, $p=0.008$, with Whites being particularly unlikely to appraise ambiguous violence as discriminatory.

Appraisals of the seriousness of the impact of the events also changed over the course of the video as a function of racist cues, $F$ $(8,400)=5.16, p<0.001, \eta^{2}=0.093$. Although Black participants were more likely to perceive a serious impact on the interview than were White participants, $F(1,200)=4.26, \quad p=0.021$, $\eta^{2}=0.038$, ethnoracial group did not interact with racist cues, $\eta^{2} s<0.02$. As depicted in Fig. 3, the introduction of either mild ambiguous or explicit racist cues resulted in perceiving the situation as more serious, $t(207)=5.92, p<0.001$. In the third

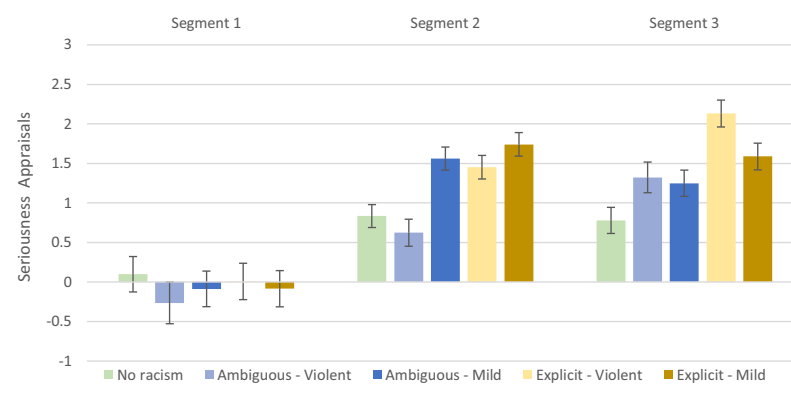

Fig. 3 Mean ratings ( + se) of the appraisals of the seriousness of the impact of the events on the interviewee as a function of racist cues (five conditions) described over the three video segments. The presence of either mild ambiguous or explicit racist cues in Segment 2 resulted in perceiving the situation as having a more serious negative impact on the target. In Segment 3, the explicit racism conditions were perceived to have a greater impact on the target compared to when racism was ambiguous, with the combination of explicit racism and violence being appraised as having a particularly serious impact.

segment of the video, explicit racism was perceived to have a greater impact on the target compared to when racism was ambiguous, $t(205)=3.30, p=0.001$. Moreover, although differences in the perceived impact of violent versus mild ambiguous events were not significant, $t(205)=0.21, p=0.831$, the combination of explicit racism and violence was appraised as having a particularly serious impact, $t(205)=2.36, p=0.019$.

Effects of racial cues on emotional reactions. An ANOVA conducted on average moment-to-moment ratings of distress within each the three video segments indicated a three-way interaction between ethnoracial group, racist cues, and video segment, $F$ $(8,398)=2.59, p=0.009, \eta^{2}=0.049$. As expected, distress was virtually absent throughout the first segment of the videos. Through the second segment, participants expressed greater distress as racist cues emerged, $t(206)=5.14, p<0.001$. However, as seen in Fig. 4, White participants indicated equal distress in response to ambiguous versus explicit racist cues, whereas Black 


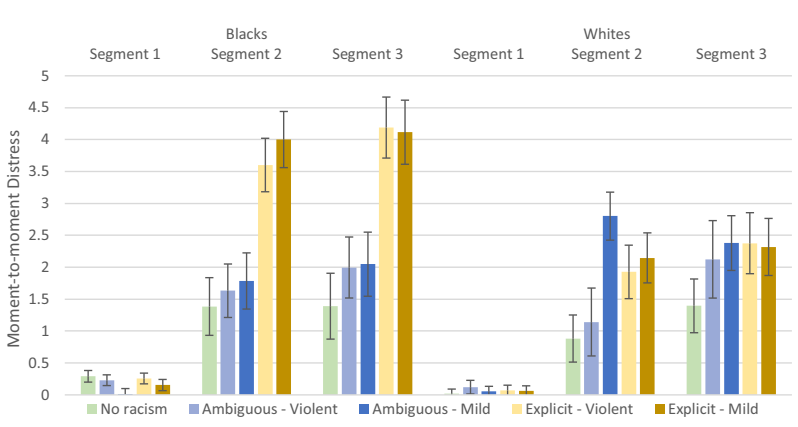

Fig. 4 Mean dial ratings ( \pm se) of moment-to-moment distress indicated through each of the three video segments ( $Y$-axis) as a function of racist cues (five conditions) among Black (left) and White (right) participants. Overall, White participants indicated equal distress in response to ambiguous versus explicit racist cues, whereas Black participants expressed significantly greater distress when the cues were explicit. Likewise, in Segment 3, Whites' distress did not vary as a function of the nature of the racist cues, whereas among Blacks, greater distress was expressed in response to explicit racism, irrespective of whether the events included violence.

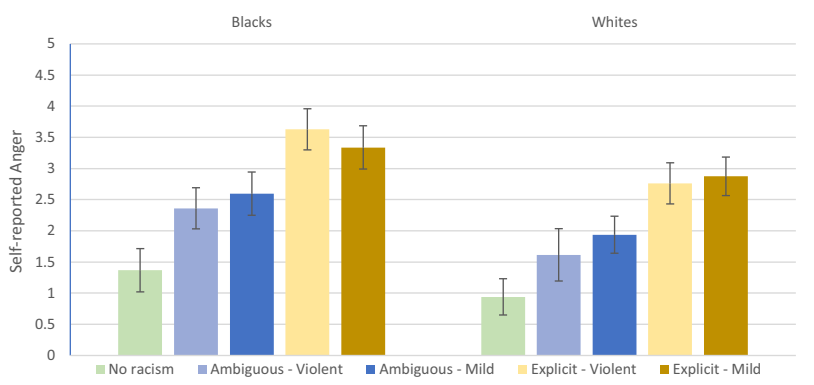

Fig. 5 Mean ratings ( + se) of self-reported anger at the end of the videos as a function of racist cues presented in each of the five video conditions. The presence of racist cues elicited greater anger, particularly in response to explicit (relative to ambiguous) racism, irrespective of whether the events were mild or violent.

participants expressed significantly greater distress when the cues were explicit, $t(206)=3.90, p<0.001$. Likewise, in the third segment, although greater distress was conveyed by both Blacks and Whites when racist cues were present, $t(203)=3.38, p=0.001$, Whites' distress did not vary as a function of the nature of the racist cues, $F(4,106)=1.42, p=0.233$. Among Blacks (Fig. 4), greater distress was expressed in response to explicit racism, irrespective of whether the events included violence, $t(93)=3.71, p<0.001$.

An ANOVA on ratings of anger taken at the end of the videos indicated that, overall, Blacks expressed greater anger $(M=2.67$, $S D=1.76)$ than did Whites $(M=2.02, \quad S D=1.60), \quad F$ $(1,200)=8.84, p=0.003, \eta^{2}=0.042$. In addition, there was a main effect of racist cues, $F(4,200)=13.38, p<0.001, \eta^{2}=0.211$, which was not moderated by ethnoracial group, $F<1$. As seen in Fig. 5, the presence of racist cues elicited greater anger, $t$ $(205)=5.97, p<0.001$, particularly in response to explicit (relative to ambiguous) racism, $t(205)=4.12, p<0.001$, irrespective of whether the events were mild or violent.

Moderators of responses to racist cues. The moderating roles of individual difference factors (past experiences of racism among Blacks; modern racist attitudes among Whites) on the effects of racist cues on appraisals and emotional reactions at the end of the

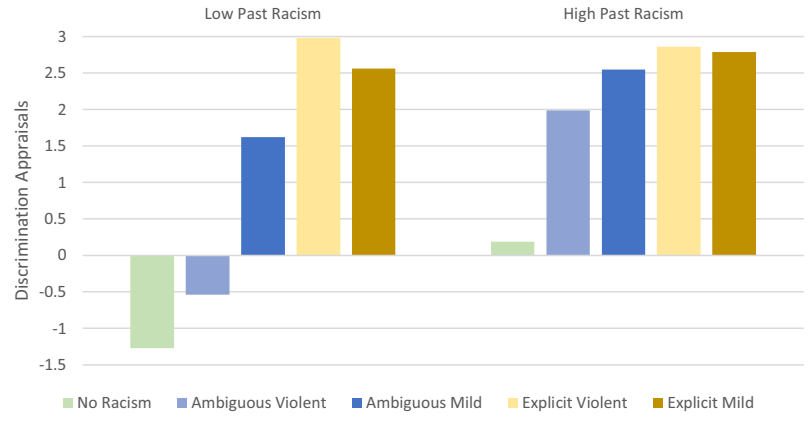

Fig. 6 Moderating effects of past racism experiences on Blacks' appraisals of whether the video scenarios were discriminatory as a function of racist cues presented in each of the five conditions. When fewer past experiences of racism were reported (1 SD below the mean), discrimination appraisals were greatest when racist cues were explicit. As past exposure to racism increased (1 SD above the mean), Black participants were more likely to regard ambiguous events as constituting discrimination.

video were assessed by means of multiple regression analyses conducted separately for each ethnoracial group.

Among Blacks, there was a significant interaction between past racism and racist cues in the videos on appraisals of whether the events were discriminatory, $F(4,88)=2.85, \quad p=0.028$, $R_{\text {cha }}^{2}=0.056$. Simple effects analyses (Fig. 6) indicated that when fewer past experiences of racism were reported, appraisals of discrimination were greatest when racist cues were explicit, $F$ $(4,88)=19.85, \quad p<0.001$. As past experience with racism increased, Black participants were more likely to regard ambiguous events as constituting discrimination, $F(4,88)=7.39$, $p<0.001$. Past racism experiences did not moderate the effects of racist video cues on the perceived seriousness of the events depicted, distress, or anger.

Whites' appraisals of the events in the videos were moderated by modern racist attitudes, $F(4,99)=6.78, \quad p<0.001$, $R_{\text {cha }}^{2}=0.072$. Simple effects analyses indicated that, as seen in Fig. 7 (left), those who were less racist were more likely to perceive discrimination when it was explicit or ambiguous and mild, $F(4,99)=52.97, \quad p<0.001$. Whites expressing higher modern racism were less likely to appraise ambiguous events as constituting discrimination, particularly when violence was involved, $F(4,99)=27.55, p<0.001$.

This moderating effect was also observed in relation to Whites' appraisals of the seriousness of the impact of the events depicted, $F(4,99)=4.36, p=0.003, R_{\text {cha }}^{2}=0.126$. Simple effects analyses (Fig. 7, right) indicated that those who were less racist were more likely to perceive the events in all four racist conditions (relative to no racism) as having serious negative implications for the target, $F(4,99)=6.63, p<0.001$. In contrast, those expressing higher modern racism only appraised explicit violent racism as having more serious consequences, $F(4,99)=4.02, p=0.005$. Modern racism did not alter patterns associated with distress or anger among Whites.

Cortisol reactivity. As it was expected that cortisol variations should correspond with levels of distress (and possibly anger), hierarchical regression analyses were conducted, wherein the area under the curve (AUC) associated with cortisol levels was regressed onto distress or anger (independent variables), followed by racist cues condition (four coded variables reflecting the orthogonal contrasts) and ethnoracial group (moderating variables), and the 2-way and 3-way interactions on subsequent steps. 


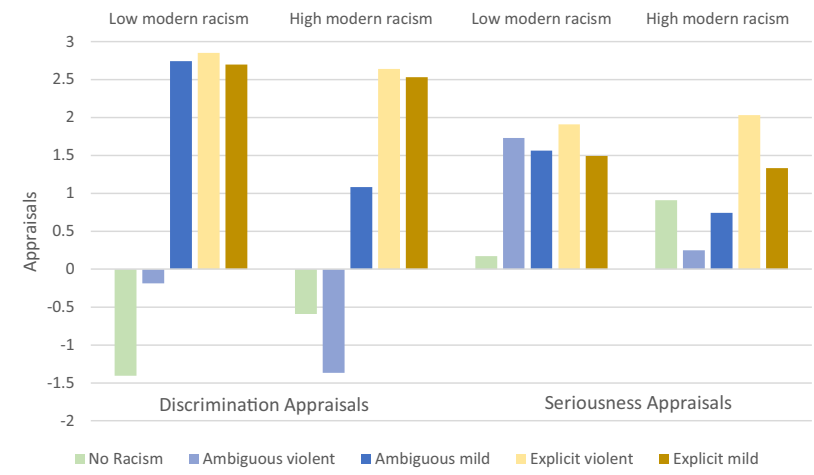

Fig. 7 Moderating effects of modern racist attitudes on Whites' appraisals of whether the video scenarios were discriminatory (left) and whether the events depicted seriously affected the target (right) as a function of racist cues presented in each of the five conditions. Whites who expressed lower modern racism (1 SD below the mean) were more likely to perceive discrimination when it was explicit (irrespective of the presence of violence) or ambiguous and mild, and were more likely to perceive the events in all four racist conditions (relative to no racism) as having serious negative implications for the target. Whites who reported higher modern racism (1 SD above the mean) were less likely to appraise ambiguous events as constituting discrimination particularly when violence was involved, and uniquely perceived negative consequences as serious when events entailed explicit violent racism.

A significant interaction between distress and ethnoracial group on cortisol AUC was demonstrated, $F(1,178)=5.57, p=0.019$, $R_{\text {cha }}^{2}=0.027$, as was the interaction between distress and racist cues condition, $F(4,174)=3.67, p=0.007, R_{\text {cha }}^{2}=0.067$. Among Blacks, greater distress was associated with higher cortisol AUC, $b=0.153$, se $=0.038, p<0.001$, whereas among Whites, this relation was not significant, $b=0.007$, se $=0.052, p=0.889$. Further, among Blacks, the positive relation between distress and cortisol AUC was especially pronounced in the two conditions conveying physical violence $\left(r_{\text {ambiguous }}=0.68, r_{\text {explicit }}=0.72\right.$, $p$ s $<$ 0.001 vs. conditions with no violence, $r=0.40, p<0.001$ ), whereas among Whites, the only condition in which this relation reached significance was when physical violence occurred and racist cues were ambiguous $\left(r_{\text {ambiguous violence }}=0.65, p=0.016\right.$, $\left.r_{\text {explicit violence }}=-0.04, p=0.894, r_{\text {no violence }}=0.01, p=0.889\right)$.

Anger was not related to cortisol AUC, irrespective of ethnoracial group or racist cues. Past experiences of racism among Blacks was not a significant moderating variable, nor was modern racism among Whites.

\section{Discussion}

Given a national policy of multiculturalism in Canada, coupled with the demographic characteristics of the resident Black population, it was of interest to assess the implications of experiences of racism for Black Canadians' emotional and cognitive reactions to such encounters, as well as for their well-being. Experiences of racism are thought to affect mental health among members of ethnoracial groups by way of heightened stress responses. Less clear are the contextual factors that help individuals to make sense of racist encounters and determine effective strategies to contend with them (Lui, 2020; Pieterse and Powell, 2016). Indeed, as previously observed (Jones et al., 2016; Lui and Quezada, 2019; Matheson et al., 2019; Tao et al., 2017), explicit and ambiguous racism in the present investigation were differentially related to emotional coping and with depressive affect. However, the interplay between these types of racism and their implications for coping strategies and stress outcomes was complex.
Typically, explicit and ambiguous racism are treated as independent constructs (or sometimes as being at opposite ends of a continuum), when in fact, as in the present study, not only were reports of such encounters correlated, but their joint consideration revealed unique patterns of relations. In particular, past experiences of explicit racism were not related to depressive affect among Blacks. But, together with greater private regard (i.e., pride in their Black identity), explicit racism was associated with greater expression of anger (anger-out), which in turn, was related to lower depressive affect. These relations are in keeping with the view that group members who cope by expressing their outrage are more likely to engage in collective actions to address racism (Becker et al., 2011; Brondolo et al., 2005; Ellemers and Barreto, 2009). In this sense, anger expression may be a highly adaptive coping response to discrimination (Matheson and Anisman, 2009). This said, the propensity to express anger that was associated with explicit racism masked a positive link between explicit racism and depressive affect that was only evident when this anger coping strategy was statistically controlled. This underlying link between racism and depressive affect may render the individual more vulnerable to stress-related disturbances, particularly when feelings of anger or hostility are prolonged (Busch et al., 2017; Pittman, 2011).

Explicit racism also played a suppressor role in the relation between ambiguous racism and depressive affect. In this regard, once the shared variance between the two types of racism was accounted for, ambiguous racist experiences were more strongly associated with depressive affect. A history of ambiguous racism was further related to greater anger-in, which in turn, predicted greater depressive affect. Ambiguity may create uncertainty not only for how to interpret the event, but also with respect to how the perpetrator may react to labelling the interaction as racist. Perhaps for this reason, when Black Canadians perceived high public regard, ambiguous racism was even more strongly associated with supressing anger. Given the socio-political context, Blacks experiencing ambiguous forms of racism might be especially concerned that the perpetrator would react to confrontation by claiming that their actions were misperceived, or that the target is simply a complainer (Garcia et al., 2010). Indeed, there is much anecdotal evidence justifying such a concern (Donovan, 2020). Moreover, suggesting that ambiguous actions are racist could instigate a cyclical interaction wherein the target's claims are responded to with further instances of negative behaviour on the part of the perpetrator (Jones et al., 2017). To the extent that anger is experienced but remains unexpressed, a 'simmering resentment' might build that could motivate collective action at a later time, as clarity regarding systemic racism evolves.

Of particular interest in the experimental study was to disentangle a common confound between the ambiguity and the severity of racist events. The majority of research assessing ambiguous racism has focused on mild microaggressions, finding similar, if not stronger relations to stress-related outcomes compared to more explicit forms of racism (Jones et al., 2016; Lui and Quezada, 2019). Although we anticipated that the effects of ambiguity might be more profound when the incident involved assault, both Blacks and Whites in the present study were less likely to appraise violence that was racially ambiguous as constituting discrimination, compared to mild ambiguous discrimination, and minimized the seriousness of the consequences for the target. In addition, racially ambiguous violence did not elicit the same level of distress or anger as when the violence was explicitly racist. It appears that violence might serve to discount ambiguous racist cues, such that individuals are more likely to attribute causality to the exceptional malevolence of the perpetrator. Albeit speculative, this may serve as a defensive strategy that, among Blacks, creates an illusion of control over one's own 
risk, or among Whites, minimizes the challenge to their collective moral standing (Leach et al., 2007). Importantly, the present study was conducted prior to the recent 2020 rise of the Black Lives Matter movement, and it is possible that with the extensive media coverage of the gratuitous violence perpetrated against Blacks (particularly in the United States), attributions of unjustified violence to racism might be more probable. However, violent intergroup conflicts have waxed and waned for over a century, and as they do so again, protective psychological dynamics may be restored.

At first blush, the results of the present study suggest considerable similarities in the responses of Black and White Canadians to racism. Both groups were more likely to appraise explicit cues as constituting discrimination, and to report stronger emotional responses to these events. However, deeper scrutiny suggests that their reactions were also fundamentally different. Specifically, across the four racialized situations described by the Black target in the videos, Whites were less likely than Blacks to appraise such encounters as discriminatory, were less likely to believe that the events described would have serious consequences for the target, and reported less distress and anger. These differences could simply be due to a reduced ability to empathize with a cross-race target (Vanman, 2016), or that the events evoked just-world beliefs and by extension a greater likelihood among Whites of blaming the victim (Dawtry et al., 2020). Indeed, although differences in appraisals depended on whether Whites endorsed modern racist attitudes (with less racist Whites being more likely to acknowledge discrimination and its serious impacts on the target), such attitudes did not alter emotional distress or anger.

The experimental study employed a unique strategy for assessing distress in response to the events in the videos. In particular, rather than retrospectively assessing distress following the video, which might be heavily influenced by demand characteristics, moment-to-moment ratings were taken as events unfolded (see also Hoggard et al., 2017). Not only did these ratings reflect greater distress among Blacks, particularly when exposed to explicit racist cues, but these distress ratings were uniquely associated with higher cortisol levels among Blacks. The relation between reported distress and cortisol levels was not evident among Whites. In addition, the relations between distress and cortisol levels were stronger among Blacks when the events included physical assault. Earlier research has been inconsistent in documenting cortisol reactions to racism, with some finding blunted responses to reminder cues of discrimination (Jamieson et al., 2013; Matheson and Anisman, 2012), or a flattening of diurnal levels, including a reduction of the early morning cortisol rise (Zeiders et al., 2014), whereas others reported elevated levels (Huynh et al., 2017; Matheson et al., 2008). It is possible that specific situational cues may produce a blunted or sensitized cortisol response to racism, which might further vary depending on the emotional reactions elicited, such as distress or shame (Dickerson and Kemeny, 2004; Matheson and Anisman, 2009).

As described earlier, elevated cortisol levels in response to stressors can have multiple adaptive functions that limit adverse psychological and physical health consequences (Anisman et al., 2018). When stressor conditions are sufficiently severe and occur on a chronic intermittent basis, as is the case with racism, allostatic overload may develop, leading to pathology (McEwen and Akil, 2020). Moreover, the accumulation of sustained social conflicts, such as racism, may lead to 'type 2' allostatic overload that requires changes of social structures, rather than individual interventions to overcome negative consequences (McEwen and Wingfield, 2003). This highlights the relevance of the sociopolitical context in Canada that, through its apparent celebration of diversity, may serve to close down challenges regarding ongoing systemic racism (Donovan, 2020).
The results of the present investigation provide some insight into the contextual factors that contribute to how racism is experienced by Blacks and reacted to by Whites. While clarity of the racist motives of the perpetrator facilitates both groups' ability to call out racism for what it is, even as Whites may report anger in response to such events, they are unlikely to experience the same depth of response to such injustices. Whites' motives in response to racism, and their efforts to understand it, have been found to vary considerably (Radke et al., 2020). Likewise, in the present study individual differences were evident, and indeed, much like Blacks with a history of racist encounters, Whites who did not endorse modern racist views were more likely to recognize ambiguous cues (when they were mild) as constituting racism, and to acknowledge the seriousness of racism on the target's well-being. While acknowledging that Blacks encounter discrimination may be an important first step in alliances to eradicate systemic racism, much like the undermining implications of Blacks' beliefs that others hold them in high (public) regard, simply talking about injustice, without explicit and tangible allied action may do more harm than good. In this regard, national policies of multiculturalism must go beyond the platitudes of celebrating cultural variations to encouraging a strong public discourse that allows for the acknowledgement of systemic racism.

\section{Data availability}

The datasets generated and analysed during the current study are available in the Scholars Portal Dataverse repository, https://doi. org/10.5683/SP2/QNBWQP (Study 1) and https://doi.org/ 10.5683/SP2/YBYX8M (Study 2).

Received: 21 July 2020; Accepted: 11 January 2021; Published online: 03 February 2021

\section{Note}

1 Black Canadians is the term used to refer to citizens or permanent residents of Canada who self-define as having full or partial sub-Saharan African descent. While the term African Canadian (paralleling African American) is used occasionally, Black people of Caribbean origin in Canada reject the term as it does not convey their uniquely Caribbean heritage. People of Colour is viewed as an especially offensive term to some Black Canadians, as it divides out and lumps together everyone who is non-White, along with its historical echoes of the term 'coloured people' (Adam, 2020).

\section{References}

Adam M (2020) Why the term 'people of colour' is offensive to so many. Ottawa Citizen. Available via https://ottawacitizen.com/opinion/adam-why-theterm-people-of-colour-is-offensive-to-so-many. Accessed 26 Dec 2020.

Anisman H, Hayley S, Kusnecov A (2018) The immune system and mental health. Wiley Blackwell, London

Beck AT, Ward CH, Mendelson M et al. (1961) An inventory for measuring depression. Arch Gen Psychol 4:561-569

Becker JC, Tausch N, Wagner U (2011) Emotional consequences of collective action participation: differentiating self-directed and outgroup-directed emotions. Pers Soc Psychol Bull 37:587-1598

Bloch KR, Taylor T, Martinez K (2020) Playing the race card: White injury, White victimhood and the paradox of colour-blind ideology in anti-immigrant discourse. Ethn Racial Stud 43:1130-1148

Bombay A, Matheson K, Anisman H (2010) Decomposing identity: differential relationships between several aspects of ethnic identity and the negative effects of perceived discrimination among First Nations adults in Canada. Cult Divers Ethn Minor Psychol 16:507-516

Branscombe NR, Schmitt MT, Harvey RD (1999) Perceiving pervasive discrimination among African Americans: Implications for group identification and well-being. J Pers Soc Psychol 77:135-149

Brittian AS, Kim SY, Armenta BE et al. (2015) Do dimensions of ethnic identity mediate the association between perceived ethnic group discrimination and depressive symptoms? Cult Divers Ethn Minor Psychol 21:41-53

Brondolo E, Thompson S, Brady N et al. (2005) The relationship of racism to appraisals and coping in a community sample. Ethn Dis 15(4):S5 
Broudy R, Brondolo E, Coakley V et al. (2007) Perceived ethnic discrimination in relation to daily moods and negative social interactions. J Behav Med 30 (1):31-43

Busch LY, Pössel P, Valentine JC (2017) Meta-analyses of cardiovascular reactivity to rumination: a possible mechanism linking depression and hostility to cardiovascular disease. Psychol Bull 143:1378-1394

Contrada RJ, Ashmore RD, Gary ML et al. (2001) Measures of ethnicity-related stress: psychometric properties, ethnic group differences, and associations with well-being. J Appl Soc Psychol 31:1775-1820

Dawtry RJ, Callan MJ, Harvey AJ, Gheorghui AI (2020) Victims, vignettes, and videos: meta-analytic and experimental evidence that emotional impact enhances the derogation of innocent victims. Pers Soc Psychol Rev 24:233-259

DeLapp RCT, Williams MT (2019) Preparing for racial discrimination and moving beyond reactive coping: a systematic review. Curr Psychiatry Res Rev 15 (1):58-71

Dickerson SS, Kemeny ME (2004) Acute stressors and cortisol responses: a theoretical integration and synthesis of laboratory research. Psychol Bull 130:355-391

Donovan D (2020) A learning moment for Erin O’Toole and Rex Murphy on racism in Canada. Ottawa Life Mag. Available via https://www.ottawalife. com/article/an-answer-to-rex-murphys-questions-on-racism-in-canada Accessed 28 Dec 2020

Dunn J, Nelson JK (2011) Challenging the public denial of racism for a deeper multiculturalism. J Intercult Stud 32:587-602

Ellemers N, Barreto M (2009) Collective action in modern times: how modern expressions of prejudice prevent collective action. J Soc Iss 65:749-768

Forrest-Bank SS, Cuellar MJ (2018) The mediating effects of ethnic identity on the relationships between racial microaggression and psychological well-being. Soc Work Res 42:44-56

Forrest-Bank SS, Jenson JM (2015) Differences in experiences of racial and ethnic microaggression among Asian, Latino/Hispanic, Black, and White young adults. J Sociol Soc Welf 42:141-161

Garcia DM, Schmitt M, Branscombe NR, Ellemers N (2010) Women's reactions to ingroup members who protest discriminatory treatment: the importance of beliefs about inequality and response appropriateness. Eur J Soc Psychol 40:733-745

Giamo LS, Schmitt MT, Outten HR (2012) Perceived discrimination, group identification, and life satisfaction among multiracial people: a test of the rejection-identification model. Cult Div Ethn Min Psychol 18:319-328

Gill R, Matheson K (2006) Responses to discrimination: the role of emotion and expectations for emotional regulation. Pers Soc Psychol Bull 32:149-161

Gong F, Xu J, Takeuchi DT (2017) Racial and ethnic differences in perceptions of everyday discrimination. Sociol Race Ethn 3:506-521

Hayes AF (2017) Introduction to mediation, moderation, and conditional process analysis. Guilford Press, New York

Hoggard LS, Jones S, Sellers RM (2017) Racial cues and racial identity: implications for how African Americans experience and respond to racial discrimination. J Black Psychol 43:409-432

Huynh VW, Huynh QL, Stein MP (2017) Not just sticks and stones: indirect ethnic discrimination leads to greater physiological reactivity. Cult Div Ethn Min Psychol 23:425-434

Jamieson JP, Koslov K, Nock MK, Mendes WB (2013) Experiencing discrimination increases risk taking. Psychol Sci 24:131-139

Jones AM (2020) In Canada, it's racism with a smile: Donovan Bailey reflects on racial inequality. CTV News. Available via https://www.ctvnews.ca/sports/incanada-it-s-racism-with-a-smile-donovan-bailey-reflects-on-racialinequality-1.4973814 Accessed 27 Dec 2020

Jones KP, Arena DF, Nittrouer CL et al. (2017) Subtle discrimination in the workplace: a vicious cycle. Indus Org Psychol 10:51-76

Jones KP, Peddie CI, Gilrane VL et al. (2016) Not so subtle: a meta-analytic investigation of the correlates of subtle and overt discrimination. J Manag 42:1588-1613

Karmali F, Kawakami K, Page-Gould E (2017) He said what? Physiological and cognitive responses to imagining and witnessing outgroup racism. J Exp Psychol 146:1073-1085

Kunstman JW, Tuscherer T, Trawalter S, Lloyd EP (2016) What lies beneath? Minority group members' suspicion of Whites' egalitarian motivation predicts responses to Whites' smiles. Pers Soc Psychol Bull 42:1193-1205

Leach CW, Ellemers N, Barreto M (2007) Group virtue: the importance of morality (vs. competence and sociability) in the positive evaluation of in-groups. J Personal Soc Psychol 93:234-249

Lilienfeld SO (2017) Microaggressions: strong claims, inadequate evidence. Psychol Sci 12:138-169

Lui PP (2020) Racial microaggression, overt discrimination, and distress: (In)direct associations with psychological adjustment. Couns Psychol 48:551-582

Lui PP, Quezada L (2019) Associations between microaggression and adjustment outcomes: a meta-analytic and narrative review. Psychol Bull 145:45-78
Lum Z (2020) Systemic racism exists in Canada. It's a fact, not an opinion. Huffington Post. Available via https://www.huffingtonpost.ca/entry/systemicracism-canada_ca_5ed93343c5b69dee016ed31f. Accessed 27 Dec 2020

Major B, Quinton WJ, McCoy SK (2002) Antecedents and consequences of attribution to discrimination: theoretical and empirical advances. In: Zanna M (ed) Advances in experimental social psychology, vol 34. Academic Press, San Diego, pp. 251-330

Matheson K, Anisman H (2012) Biological and psychosocial responses to discrimination. In: Jetten J, Haslam SA, Haslam C (eds) The social cure. Psychology Press, London, pp. 133-154

Matheson K, Anisman H (2009) Anger and shame elicited by discrimination: moderating role of coping on action endorsements and salivary cortisol. Eur J Soc Psychol 39:163-185

Matheson K, Foster MD, Bombay A et al. (2019) Trauma, perceived discrimination, and distress symptoms in socially marginalized groups. Front Psychol $10: 416$

Matheson K, Jorden S, Anisman H (2008) Relations between trauma experiences and psychological, physical and neuroendocrine functioning among Somali refugees: mediating role of coping with acculturation stressors. J Immig Min Health 10:291-304

McConahay JB (1986) Modern racism, ambivalence, and the Modern Racism Scale. In: Dovidio JF, Gaertner SL (eds) Prejudice, discrimination, and racism. Academic Press, San Diego, pp. 91-125

McEwen BS, Akil H (2020) Revisiting the stress concept: implications for affective disorders. J Neurosci 40:12-21

McEwen BS, Wingfield JC (2003) The concept of allostasis in biology and biomedicine. Horm Behav 4:2-15

Mercer SH, Zeigler-Hill V, Wallace M, Hayes DM (2011) Development and initial validation of the Inventory of Microaggressions Against Black Individuals. J Counsel Psychol 58:457-469

Michaud K, Matheson K, Kelly O, Anisman H (2008) Impact of stressors in a natural context on release of cortisol in healthy adult humans: meta-analysis. Stress 11:177-197

Neuman K (2019) Race relations in Canada 2019 survey. Environics Institute. Available via https://www.environicsinstitute.org/projects/projectdetails/race-relations-in-canada-2019.

Operario D, Fiske S (2001) Ethnic identity moderates perceptions of prejudice: judgments of personal versus group discrimination and subtle versus blatant bias. Pers Soc Psychol Bull 27:550-561

Passini S (2019) The indifference that makes a difference: why unconcern for minorities disguises prejudicial attitudes. J Moral Educ 48:263-274

Pieterse A, Powell SA (2016) Theoretical overview of the impact of racism on People of Color. In: Alvarez AN, Liang CTH, Neville HA (eds) Cultural, racial, and ethnic psychology book series. The cost of racism for People of Color: contextualizing experiences of discrimination. American Psychological Association, Washington, pp. 11-30

Pieterse AL, Todd NR, Neville HA, Carter RT (2012) Perceived racism and mental health among Black American adults: a meta-analytic review. J Counsel Psychol 59:1-9

Pittman CT (2011) Getting mad but ending up sad: the mental health consequences for African Americans using anger to cope with racism. J Black Stud 42:1106-1124

Pruessner JC, Kirschbaum C, Meinlschmid G, Hellhammer DH (2003) Two formulas for computation of the area under the curve represent measures of total hormone concentration versus time dependent change. Psychoneuroendocrinology 28:916-931

Quinn DM, Williams MK, Quintana F et al. (2014) Examining effects of anticipated stigma, centrality, salience, internalization, and outness on psychological distress for people with concealable stigmatized identities. PLoS ONE 9: e96977

Radke HRM, Kutlaca M, Siem B et al. (2020) Beyond allyship: motivations for advantaged group members to engage in action for disadvantaged groups. Pers Soc Psychol Rev 24:291-315

Ray B, Preston V (2015) Working with diversity: a geographical analysis of ethno-racial discrimination in Toronto. Urban Stud 52:1505-1522

Sapolsky RM, Romero LM, Munck AU (2000) How do glucocorticoids influence stress responses? Integrating permissive, suppressive, stimulatory, and preparative actions. Endocr Rev 21:55-89

Schmader T, Croft A, Scarnier M et al. (2012) Implicit and explicit emotional reactions to witnessing prejudice. Group Proc Intergr Rel $15: 379-392$

Schmitt MT, Branscombe NR, Postmes T, Garcia A (2014) The consequences of perceived discrimination for psychological well-being: a meta-analytic review. Psychol Bull 140:921-948

Sellers RM, Copeland-Linder N, Martin PP, Lewis RH (2006) Racial identity matters: the relationship between racial discrimination and psychological functioning in African American adolescents. J Res Adol $16: 187-216$ 
Sellers RM, Smith M, Shelton JN et al. (1998) Multidimensional model of racial identity: a reconceptualization of African American racial identity. Pers Soc Psychol Rev 2:18-39

Siegel JM (1986) The multidimensional anger inventory. J Pers Soc Psychol 51:191-200

Sosoo EE, Bernard DL, Neblett Jr EW (2019) The influence of internalized racism on the relationship between discrimination and anxiety. Cult Div Ethnic Min Psychol 26:570-580

Statistics Canada (2019). Diversity of Black population in Canada: an overview. Available via https://www150.statcan.gc.ca/n1/en/pub/89-657-x/89-657x2019002-eng.pdf?st=j0qEq2yM. Accessed 26 Dec 2020.

Stelkia K (2020) Police brutality in Canada: a symptom of structural racism and colonial violence. Yellowhead Institute. Available via https:// yellowheadinstitute.org/2020/07/15/police-brutality-in-canada-a-symptomof-structural-racism-and-colonial-violence/. Accessed 27 Dec 2020.

Sue DW (2010) Microaggressions in everyday life: Race, gender, and sexual orientation. Wiley Press, New Jersey

Tao KW, Owen J, Drinane JM (2017) Was that racist? An experimental study of microaggression ambiguity and emotional reactions for racial-ethnic minority and white individuals. Race Soc Probl 9:262-271

Torres L, Reveles AK, Mata-Greve F et al. (2020) Reactions to witnessing ethnic microaggressions: an experimental study. J Social Clin Psychol 39:141-164

Tougas F, Brown R, Beaton A, Joly S (1995) Neo-sexism: plus ca change, plus c'est pareil. Pers Soc Psychol Bull 21:842-849

Van Zomeren M, Spears R, Fischer AH, Leach CW (2004) Put your money where your mouth is! Explaining collective action tendencies through group-based anger and group efficacy. J Pers Soc Psychol 87:649-664

Vanman EJ (2016) The role of empathy in intergroup relations. Curr Opin Psychol $11: 59-63$

Zeiders KH, Hoyt LT, Adam EK (2014) Associations between self-reported discrimination and diurnal cortisol rhythms among young adults: the moderating role of racial-ethnic minority status. Psychoneuroendocrinology $50: 280-288$

\section{Acknowledgements}

This research was supported by a research grant from the Canadian Institutes for Health Research (grant number \#86477).

\section{Competing interests}

The authors declare no competing interests.

\section{Additional information}

Correspondence and requests for materials should be addressed to K.M.

Reprints and permission information is available at http://www.nature.com/reprints

Publisher's note Springer Nature remains neutral with regard to jurisdictional claims in published maps and institutional affiliations.

(c) (i) Open Access This article is licensed under a Creative Commons Attribution 4.0 International License, which permits use, sharing, adaptation, distribution and reproduction in any medium or format, as long as you give appropriate credit to the original author(s) and the source, provide a link to the Creative Commons license, and indicate if changes were made. The images or other third party material in this article are included in the article's Creative Commons license, unless indicated otherwise in a credit line to the material. If material is not included in the article's Creative Commons license and your intended use is not permitted by statutory regulation or exceeds the permitted use, you will need to obtain permission directly from the copyright holder. To view a copy of this license, visit http://creativecommons.org/ licenses/by/4.0\%.

(c) The Author(s) 2021 